\title{
INVESTIGATION OF SOME ORGANIC POLLUTANTS IMPACT ON PHYSICO-CHEMICAL CHARACTERISTICS OF PLANTLETS
}

\author{
Romică CREŢ̧U \\ "Dunarea de Jos" University of Galati, Romania \\ e-mail: romy_cretu@yahoo.com
}

\begin{abstract}
The cleaning process plays an important role in industry. On the other hand, the presence of detergents in soil can greatly impact on the environment. Therefore, the present study was conducted to evaluate the impact of two complex pollutants on some plantlets, e.g. Phaseolus vulgaris and Petroselinum crispum. In this context, this article uses various physico-chemical methods to compare the impact of non-biodegradable liquid detergent (a mixture of different compounds which contain isothiazolinone, methylisothiazolinone and 2-bromo-2-nitropropane-1,3diol) on the environment with the one based on biodegradable origin (without 2bromo-2-nitropropane-1,3-diol). Moreover, additional investigations showed the significant decrease in total carotenoids content and colour parameters with pollutant concentrations $(0.125 \div 0.5 \%)$. Based on the results from the analysis performed in this paper, the contamination of soil with liquid detergents can have adverse effects on plants metabolism with plantlets height and number of leaves variation. Although there is no very strict correlation between the biometrical parameters and the concentration of the detergents used in this study, as a result of the individual enzymatic response of the plantlets to the aggression of the detergents, it is obvious that the plantlets' metabolism is negatively influenced by the presence of both detergents. Also, the content of carotenoids and xanthophylls decreased in the case of studied samples, at the highest concentration (0.5\%) of non-biodegradable detergent (Phaseolus vulgaris samples) and lower concentration $(0.125 \%)$ of biodegradable detergent (Petroselinum crispum samples).
\end{abstract}

KEYWORDS: biodegradable, without environmental compatibility, biometrical parameters, carotenoids and xanthophylls, colour

\section{Introduction}

The anthropic pollution by various activities in industry or transport has been amplified in the last decades as compared to the natural pollution, whose effects are minimal. Some pollutants may accumulate in organisms producing the phenomenon of biological amplification [1].

The cleaning process plays an important role in industry [2]. On the other hand, according to Uzma et al. [3] the presence of detergents in soil and water (where they can be found accidentally) can greatly impact on the environment. According to [4], it is compulsory to check the quality of the soils. Considering the possibility of some pollutants to exist in the soil, it is important to analyse them and to inform the users.
Many of the chemical substances present in the used detergent products on plantlets, e.g. common beans (Phaseolus vulgaris) and the parsley (Petroselinum crispum) are characterised by a certain degree of toxicity. Thus, the impact of used liquid detergents on plants is a complex problem. The origin of the grown species is the spontaneous parsley (Petroselinum crispum sylvestre), widely spread around the Mediterranean. Parsley is an allogamous plant, which means the pollination is done indirectly by insects [5].

This study focuses on specific modifications of the physico-chemical characteristics of some plantlets, e.g. Phaseolus vulgaris and Petroselinum crispum, induced by used detergents present in the soil, both bio-based and without environmental compatibility. The contents in chlorophyll (total chlorophyll) and carotenoids, known as bio-indicators 
to monitor a variety of contaminants in the ecosystem [6] will also be evaluated.

\section{Experimental Details}

\subsection{Plant material}

The subjects were selected, after a previous documentation, on the basis of their growth and development characteristics [5]. The plantlets were grown in a "green-laboratory" at "Dunarea de Jos" University of Galati, Romania. The germination of the beans (indirect light coming from a window facing north) was monitored for 21 days, the conditions of the experiment being preserved till the moment when the plant reached the necessary stage of development to be harvested and planted into new recipients with fertile soil.

\subsection{Detergents}

The biodegradable detergents (which were purchased in local supermarkets from Galati, Romania) are non-toxic for the environment and do not contain phosphates, perfumes or synthetic dyes.

In order to study the impact of detergents upon the plants we used various concentrations of detergents, keeping in mind the recommendations of the producers regarding their use.

\subsection{Weight ratio of chlorophylls and carotenoid analyses}

Chlorophyll content was determined according to Lichtenthaler and Buschmann [7] with some modifications. The pigments were extracted in $80 \%$ acetone three times for $90 \mathrm{~min}$ extraction time and 1 min homogenization time. After this process for the optimization of the extractions, ultrasonication was used for $3 \mathrm{~min}$. Then the samples were taken and

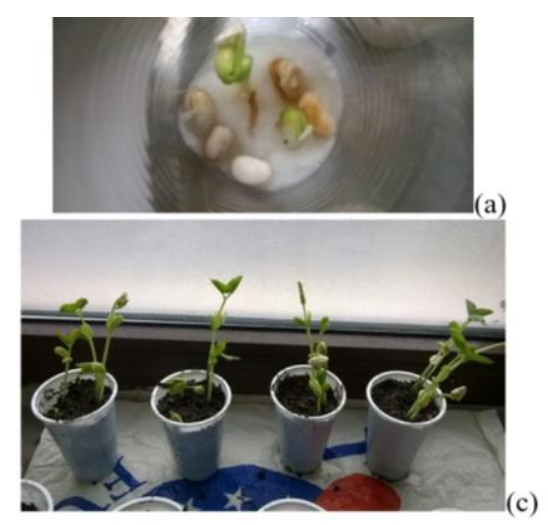

underwent centrifugation $(4000 \mathrm{x}$ g, $10 \mathrm{~min}$, refrigerated at $4{ }^{\circ} \mathrm{C}$ ) to separate cells from solvent using a Hettich Universal 320 centrifuge. Then the solution/supernatant was used for detection of chlorophyll content by UV-Vis spectrophotometry (UV-Vis Double Beam PC 8 Auto Scanning cell UVD-3200, Lobomed, INC.) at the maximum absorption wavelengths for chlorophylls a and b, respectively [8-10]. The concentration of chlorophylls and the sum of carotenoids were determined by the equation (1).

$$
\begin{aligned}
& c_{a}(\mu \mathrm{g} / \mathrm{mL})=12.25 \cdot \mathrm{A}_{663.2}-2.79 \cdot \mathrm{A}_{646.8} \\
& \mathrm{c}_{\mathrm{b}}(\mu \mathrm{g} / \mathrm{mL})=21.50 \cdot \mathrm{A}_{646.8}-5.10 \cdot \mathrm{A}_{663.2}
\end{aligned}
$$$$
\mathrm{c}_{\mathrm{x}+\mathrm{c}}(\mu \mathrm{g} / \mathrm{mL})=\left(1000 \cdot \mathrm{A}_{470}-1.82 \mathrm{c}_{\mathrm{a}}-82.02 \mathrm{c}_{\mathrm{b}}\right) / 198
$$

where $\mathrm{c}_{\mathrm{a}}=$ chlorophyll $a ; \mathrm{c}_{\mathrm{b}}=$ chlorophyll $b ; \mathrm{c}_{\mathrm{x}+\mathrm{c}}=$ carotenoids, $\mathrm{A} \lambda=$ absorbance at $\lambda(\mathrm{nm})$. The pigment concentrations are given in $\mu \mathrm{g} / \mathrm{mL}$ extract solution.

\subsection{Determination of the colour stability}

Colour stability was determined using the colour coordinates which were computed in the CIELAB system in a CIE D $65 / 10^{\circ}$ observer conditions [11]. The results were expressed as trichromatic parameters.

\section{Experimental results}

The studied plantlets with and without added detergents in topsoil with different detergent concentration were cultivated and some physicochemical parameters were determined. When the plants reached the development stage and they could be harvested and replanted, they were transferred into recipients with fertile soil employing $180 \mathrm{~mL}$ singleuse plastic beakers, where $50 \mathrm{~g}$ of flower soil had been introduced.

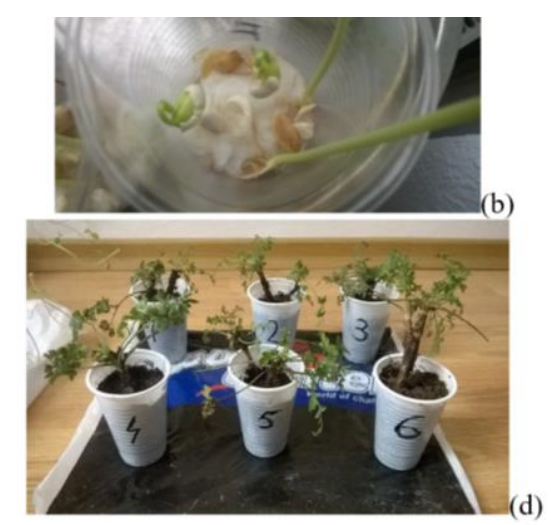

Fig. 1. Various stages of development during germination (a) and (b) for Phaseolus vulgaris. Phaseolus vulgaris offshoots an early stage (c). Petroselinum crispum plantlets an early stage (d) 
The Phaseolus vulgaris plantlets were studied under laboratory conditions identical to those used in the case of Petroselinum crispum (Figure 1).

\subsection{Biometric parameters analysis}

During the study, the plantlets were observed in their first stage of vegetative development through the analysis of certain biometrical parameters such as: high development and the number of leaves as well as colour changes or various irregularities that appeared during the experiment. On the basis of the results obtained, the 6 samples of Phaseolus vulgaris placed under scrutiny ( 3 plantlets under the effect of the bio detergent, 3 plantlets under the effect of the environment incompatible detergent) displayed heights between 26 and $40 \mathrm{~cm}$. Interestingly, for the duration of the experiments (14 days of detergent treatment), the impact of the liquid detergents upon the plantlets studied at their incipient stage indicated that the heights of the Phaseolus vulgaris plantlets remain constant only when using the nonbiodegradable detergent in concentration of $0.125 \%$. This indicates the fact that the presence of the detergent induces a totally inhibiting effect upon the plantlets' growth. In the other cases, a more or less significant growth in the plantlets' height was recorded (Figure 2).

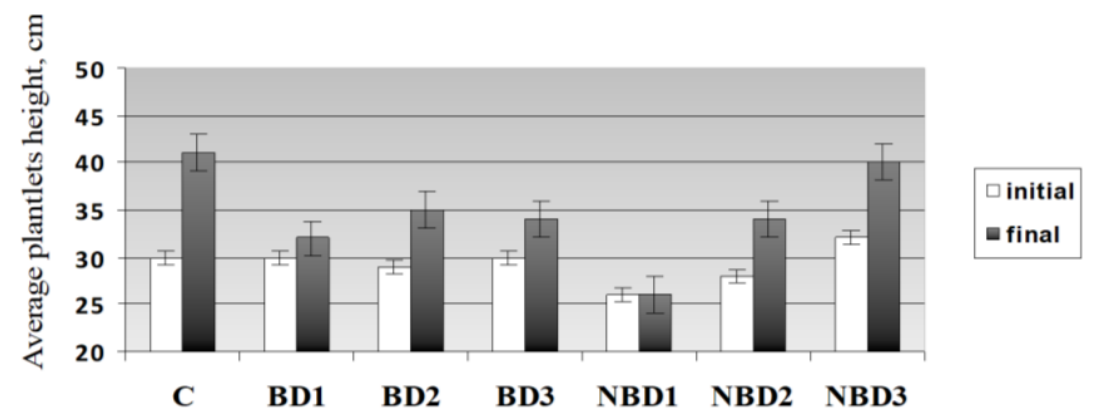

Fig. 2. The effect of detergents (different concentrations: BD1 - biodegradable liquid detergent $0.125 \%$, BD2 - biodegradable liquid detergent $0.25 \%$, BD3 - biodegradable liquid detergent $0.5 \%$ and NBD1 - non - biodegradable liquid detergent $0.125 \%$, NBD2 - non - biodegradable liquid detergent $0.25 \%, N B D 3$ - non - biodegradable liquid detergent 0.5\%; $C$ - control sample, without detergent) on the total number of the plantlets height for Phaseolus vulgaris. Vertical bars represent standard deviation of the mean $(n=3)$

The data in Figure 2 show that the largest growth in height $(25 \%)$ happens when using the environment incompatible detergent (which contains isothiazolinone, methylisothiazolinone and 2-bromo2-nitropropane-1,3-diol) with the highest concentration. The same impact of detergents was also noticed in the case of the Petroselinum crispum species (data not shown). It is worth mentioning the fact that the growth in height of the sample plantlets was of $36.66 \%$. It was also noticed that spreading the detergents over the soil where the two species were planted determines, in some cases, a decrease in the number of leaves as compared to the plantlets of the witness lot (Figure 3). The differences recorded between the impacts of the two types of detergent are significant for Phaseolus vulgaris.

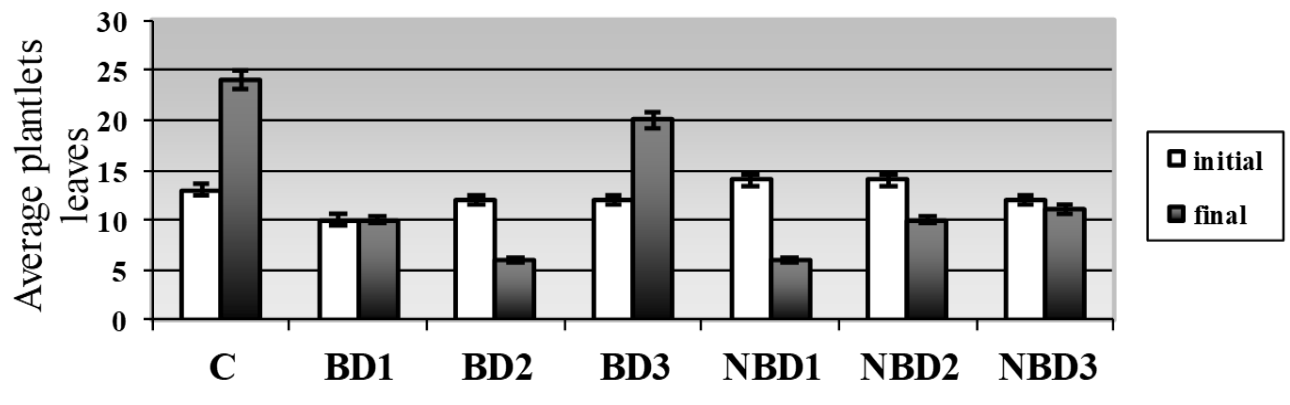

(a) 

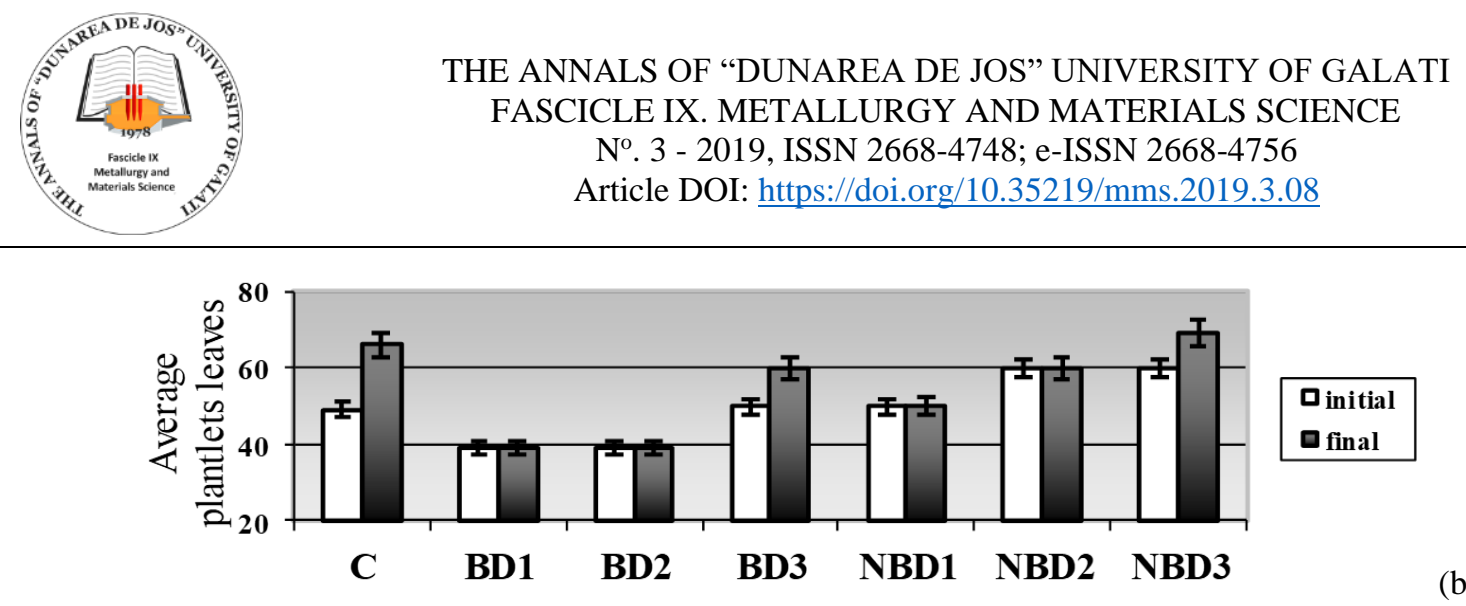

(b)

Fig. 3. The effect of detergents on the total number of the plantlets leaves for Phaseolus vulgaris (a) and Petroselinum crispum (b). The legend as explained in Fig. 2

After analyzing the data in Figure 3, one can see that this biometric parameter depends decisively on the interaction between the species of the plantlet and the type of detergent. Thus, although the number of leaves of the Phaseolus vulgaris lot placed under scrutiny was sometimes larger than that of the witness lot, the differences that appear depend on the type of detergent. There was a significant inhibition of the leaf number multiplication in the case of all samples when using non-biodegradable detergent. Moreover, the results show that whenever they get into contact with this type of detergent, the plants lose leaves no matter what concentration of detergent was used.

The highest growth in the number of leaves $(20 \%)$ happens in the presence of the biodegradable detergent with the highest concentration, although it is lower as compared to the concentration of the witness sample (35\% approximately) as a consequence of the impact the detergent has upon the plantlets metabolism. However, the values corresponding to the biodegradable detergents $(0.125 \%$ and $0.25 \%$ ) shown in Figure 3 (b) suggest a significant homogeneity regarding the leaf number of the Petroselinum crispum in relation with the detergent concentration.
Despite the fact that there is no very strict correlation between the biometrical parameters and the concentration of the detergents used in this study, as a result of the individual enzymatic response of the plantlets to the aggression of the detergents, it is obvious that the plantlets metabolism is negatively influenced by the presence of both detergents.

\subsection{Weight ratio of chlorophylls and total carotenoids analysis}

The same results were obtained in the case of samples treated with non-degradable detergent. Knowing from the specialized literature that the carotenoid pigments play a significant part in photosynthesis [12], I may assume, as in the case of chlorophyll, that certain organic substances from the composition of detergents interfere with the carotenoids' action mechanism. Moreover, the photosynthesis provides carbohydrate for plant growth [13].

The ratio between chlorophyll $a$ and chlorophyll $b$ is an indicator of how the photosynthesis process unfolds.

Table 1. The weight ratio of Chls $a$ and $b$ to total carotenoids, $(a+b) /(x+c)$ in the case of Phaseolus vulgaris. Abbreviations: $(a+b)$ represent the total chlorophylls $a$ and $b ;(x+c$, xanthophylls and carotenes (total carotenoids)

\begin{tabular}{lcccc}
\hline \multirow{2}{*}{ Detergent type } & \multirow{2}{*}{ Control sample } & \multicolumn{3}{c}{ Detergent application concentration (\%) } \\
\cline { 3 - 5 } & \multirow{2}{*}{ BD } & 0.125 & 0.25 & 0.5 \\
NBD & \multirow{2}{*}{4.265} & 2.274 & 2.113 & 3.094 \\
& & 2.001 & 2.341 & 2.759 \\
\hline
\end{tabular}

Table 2. The weight ratio of Chls $a$ and $b$ to total carotenoids, $(a+b) /(x+c)$ in the case of Petroselinum crispum. Abbreviations: see Table 1

\begin{tabular}{lcccc}
\hline \multirow{2}{*}{ Detergent type } & \multirow{2}{*}{ Control sample } & \multicolumn{3}{c}{ Detergent application concentration(\%) } \\
\cline { 3 - 5 } & \multirow{2}{*}{ S.114 } & 0.125 & 0.25 & 0.5 \\
\hline NBD & 5.111 & 4.095 & 5.079 \\
& & 2.156 & 3.258 & 4.021 \\
\hline
\end{tabular}

Moreover, the ratio between the quantities of chlorophyll $a$ and chlorophyll $b$ (Chls $a$ and $b$ ) is an indicator of the optimum functionality of photosynthesis, as well as of the adaptation to the 
action of certain harmful factors. The ratio between the quantities of chlorophyll $a$ and $b$ and the total quantity of carotenoid (xanthophylls and carotenoids), respectively $(a+b) /(x+c)$, is an indicator of how vigorous the plant is. Usually, the $(a+b)(x+c)$ ratio has values between 4.2 and 5 for the plants and leaves constantly exposed to sun light and values between 5.5 and 7.0 for plants and leaves exposed to shadow. Generally, the decrease of the value of the $(a+b)(x+c)$ ratio is an indicator of stress and disturbance of the photosynthesis process in the plantlets, which can be expressed by a sudden collapse in the production of chlorophyll as compared to carotenoids. Thus, the leaves become yellow-green and presents low values for the $(\mathrm{a}+\mathrm{b})(\mathrm{x}+\mathrm{c})$ ratio $(3.5$ or even 2.5 up to 3.0) as the plant deteriorates under the impact of the aggressing factor [14]. The results of this study are similar to findings reported by Lichtenthaler and Buschmann [7]. So, the experimental data given in Tables 1 and 2 emphasize the negative impact upon the studied plants in correlation with the presence of the detergents.

It is noticeable that in both cases the $(a+b) /(x+c)$ ratio decreases for all concentrations of detergent applied to the soil in which the plantlets developed. In both cases, the highest stress corresponds to the nonbiodegradable detergent $(0.125 \%)$, this one being the fastest to reach the roots of the plantlets. However, in the case of Phaseolus vulgaris, under the abovementioned experimental conditions, the stress induced by the detergents is higher than in the case of Petroselinum crispum.

Based on the results from the analysis performed in this paper, the content of carotenoids and xanthophylls decreased less in the case of the parsley samples, at the highest concentration of detergent, both biodegradable and non-biodegradable (Figure 4a).
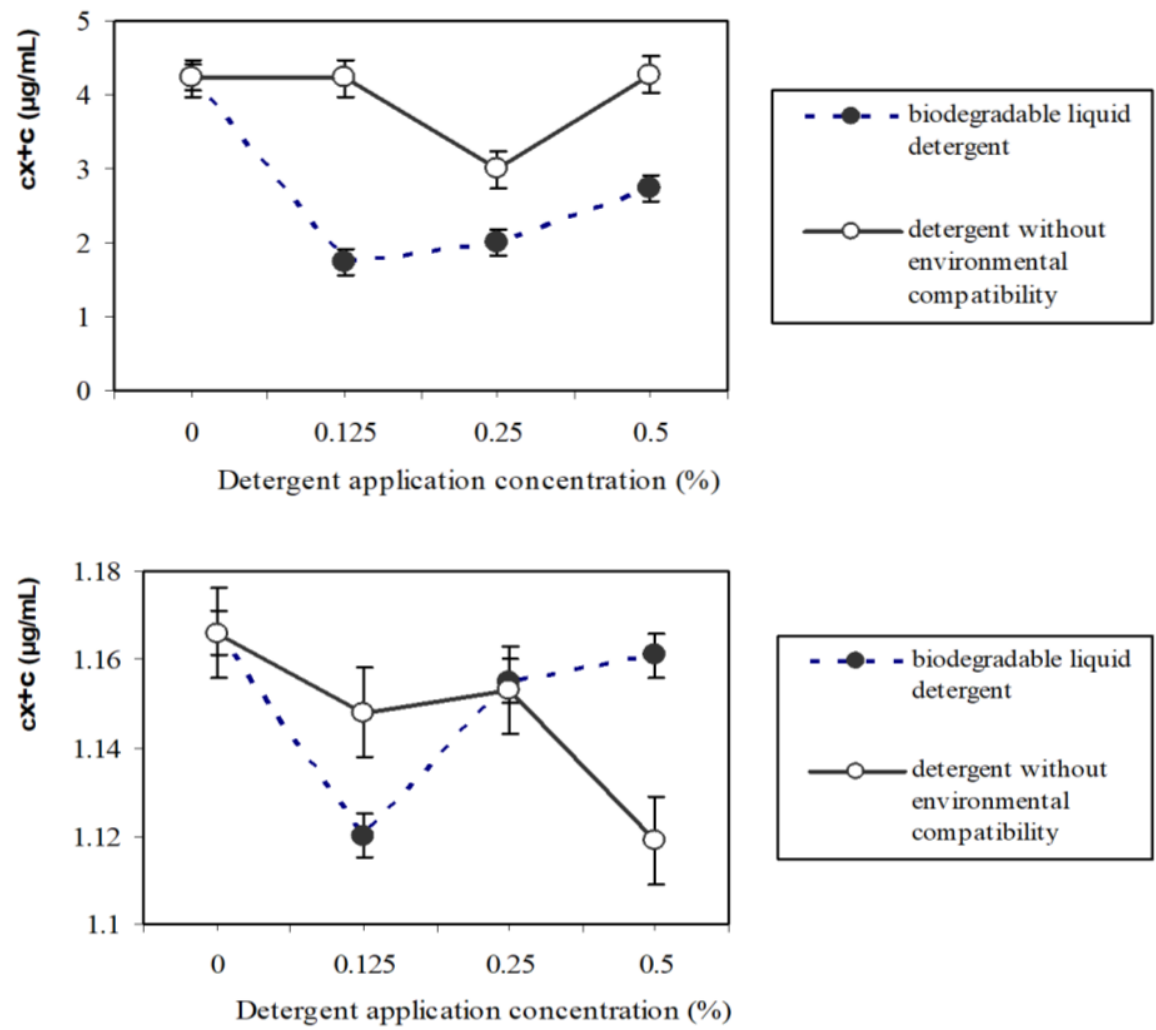

(a)

(b)

Fig. 4. Change of the carotenoids in extracts from Petroselinum crispum (a) and Phaseolus vulgaris (b) plantlets materials treated with biodegradable detergent and detergent without environmental compatibility (see legend). $c_{x+c}(\mu \mathrm{g} / \mathrm{ml})$ represent the concentration of carotenoids

$$
(x+c=x a n t h o p h y l l s \text { and carotenes })
$$

On the other hand, when biodegradable detergent was used, the lowest concentrations of detergent $(0.125 \%)$ had the highest impact, where carotenoids and xanthophylls decreased by $58.91 \%$.
Interestingly, in the case of the samples treated with non-biodegradable detergent, the decrease is of only $0.17 \%$, which indicates a higher resistance of parsley to this type of detergent at this concentration. At the highest concentrations $(0.5 \%)$, carotenoids and 
xanthophylls decreased less, $35.5 \%$ in the case of the sample treated with biodegradable detergent and only $0.12 \%$, in the case of the sample treated with nonbiodegradable detergent. These results suggest that the biodegradable detergent has a far deeper negative impact on carotenoids and xanthophylls from the parsley samples.

Similarly, to the case of the chlorophyllous pigments from the parsley samples, the impact of the detergents upon the carotenoids and xanthophylls from the bean samples was similar only for the lowest concentration of detergent (Figure 4-b). Among the samples treated with biodegradable detergent, the highest influenced was recorded in the case of the bean sample treated with $0.125 \%$ detergent, when the content of carotenoids and xanthophylls decreased by $3.95 \%$ as compared to the witness sample. On the other hand, in the case of the sample treated with nonbiodegradable detergent $(0.125 \%)$, the biosynthesis of carotenoids and xanthophylls decreased only by $1.54 \%$ as compared to the witness sample. However, the bean sample treated with the highest concentration of non-biodegradable detergent $(0.5 \%)$ is the most affected, the content of carotenoids and xanthophylls decreasing by $4 \%$ as compared to the witness sample. When biodegradable detergent $(0.5 \%)$ was used, the decrease was of only $0.26 \%$.

The plantlets response to the action of pollutants shows the less harmful impact of the biodegradable detergent at this concentration, under the conditions of the experiments. Similar conclusions (in the cases of detergent without environmental compatibility) were obtained by Pongooni and Sasikala [15] according to which the higher concentration of detergent is toxic to the plant growth.

Moreover, in accordance with the previous studies [16] the presence of the liquid detergents in the soil, irrespective of their type, may affect irreversibly (by changes in biochemical parameters) the plantlets developing and pollination of the Phaseolus vulgaris and Petroselinum crispum plants, given their having a direct and, respectively, indirect pollination (a possibly aggressive effect aggressive upon insects).

\subsection{The color evolution in the extract}

In Table 3. are presented the experimental results obtained on the localization of the extracts color in the case of parsley samples, in accordance with the CIELAB color system.

Table 3. Chromatic characteristics (CIE D $65 / 10^{\circ}$ illuminat/observer conditions) for parsley samples

\begin{tabular}{|c|c|c|c|c|c|c|c|c|}
\hline \multirow{2}{*}{ Sample } & \multicolumn{3}{|c|}{ Chromatic coordinates } & \multirow{2}{*}{$\mathrm{a}^{*} / \mathrm{b}^{*}$} & \multirow{2}{*}{$\left(\mathrm{a}^{*} / \mathrm{b}^{*}\right)^{2}$} & \multirow{2}{*}{$\mathrm{C}^{*}{ }_{\mathrm{ab}}$} & $\mathrm{s}$ & \multirow{2}{*}{$\mathrm{h}_{\mathrm{ab}}$} \\
\cline { 2 - 6 } & $\mathrm{L}^{*}$ & $\mathrm{a}^{*}$ & $\mathrm{~b}^{*}$ & & & & \\
\hline $\mathrm{C}$ & 80.30992 & -43.9832 & 73.80029 & -0.59598 & 0.355187 & 85.91276 & 1.069765 & 120.77 \\
\hline $\mathrm{NBD}_{1}$ & 85.91638 & -33.1759 & 55.30182 & -0.59991 & 0.359888 & 64.48979 & 0.750611 & 120.8 \\
\hline $\mathrm{NBD}_{2}$ & 86.57334 & -27.1958 & 52.38301 & -0.51917 & 0.26954 & 59.02197 & 0.681757 & 117.29 \\
\hline $\mathrm{NBD}_{3}$ & 82.65858 & -36.0706 & 61.37109 & -0.58775 & 0.345446 & 71.18639 & 0.861210 & 120.47 \\
\hline $\mathrm{BD}_{1}$ & 90.13535 & -27.5247 & 44.26251 & -0.62185 & 0.386699 & 52.12273 & 0.578272 & 122 \\
\hline $\mathrm{BD}_{2}$ & 90.51459 & -25.5829 & 44.54163 & -0.57436 & 0.329888 & 51.36575 & 0.567486 & 119.89 \\
\hline $\mathrm{BD}_{3}$ & 86.04945 & -33.2269 & 57.52794 & -0.57758 & 0.333596 & 66.43409 & 0.772046 & 120 \\
\hline
\end{tabular}

The experimental results highlight that in the case of the parsley samples, there is a bathochromic shift from the control sample to the sample treated with the highest concentration of detergent. More than that, the high degree of uniformity of the CIELAB color space offers the possibility of a good chromatic characterization of the samples analyzed. Thus, according to Table 1, significant differences (10.2 for BD and 6.26 for NBD sample) regarding the variation in brightness $\left(\mathrm{L}^{*}\right)$ are for $0.25 \%$ detergent concentrations. The smallest variations in brightness (5.74 for $\mathrm{BD}$ and 2.35 for NBD sample) were obtained for the highest concentration $(0.5 \%)$ of pollutant, probably due to its slower permeation to roots (under the conditions of the experiment). Also, the parameter $a^{*}$ (the red degree) values being lower than those of parameter $b^{*}$ (the yellow degree), it is obvious that the red index tends towards subunit values. Also, in this context, the chroma $\left(\mathrm{C}^{*}{ }_{\mathrm{ab}}\right)$ with the lowest values was obtained for the situation when the parsley came in contact with the biodegradable detergent. This fact correlates with a lower intensity of the color of the parsley in this case.

These results expressed by the chromatic parameters highlighted above are supported by another parameters of color characterization (saturation, $\mathrm{s}$ and hue angle, $\mathrm{h}_{\mathrm{ab}}$ ). A slightly lower hue angle was observed when the parsley was treated with biodegradable detergent. Similarly, information regarding the chromatic parameters in the case of the bean samples was obtained (Table 4).

Based on the results from the analysis performed in this paper, in the bean seedlings a color closure (by decreasing the parameter $\left.L^{*}\right)$ it is observed when non-biodegradable detergent of $0.25 \%$ concentration 
was used. Moreover, only in the case of the $\mathrm{NBD}_{1}$ and $\mathrm{NBD}_{3}$ the variation of the hue angle is greater than in the previous case, respectively the parsley seedlings.

Table 4. Chromatic characteristics (CIE D 65/10 illuminat/observer conditions) for bean samples

\begin{tabular}{|c|c|c|c|c|c|c|c|}
\hline \multirow{2}{*}{ Sample } & \multicolumn{3}{|c|}{ Chromatic coordinates } & \multirow{2}{*}{$\mathrm{a}^{*} / \mathrm{b}^{*}$} & \multirow{2}{*}{$\left(\mathrm{a}^{*} / \mathrm{b}^{*}\right)^{2}$} & \multirow{2}{*}{$\mathrm{C}_{\mathrm{ab}}{ }^{*}$} & \multirow{2}{*}{$\mathrm{h}_{\mathrm{ab}}$} \\
\cline { 2 - 6 } & $\mathrm{L}^{*}$ & $\mathrm{a}^{*}$ & $\mathrm{~b}^{*}$ & -0.67617 & 0.457208 & 47.52733 & 124.05 \\
\hline $\mathrm{C}$ & 90.84741 & -26.6219 & 39.37157 & -0.053 & 124.07 \\
\hline $\mathrm{NBD}_{1}$ & 76.31048 & -16.9783 & 19.6419 & -0.86439 & 0.747174 & 25.96281 & 116.57 \\
\hline $\mathrm{NBD}_{2}$ & 93.28303 & -6.48838 & 12.95004 & -0.50103 & 0.251032 & 14.48457 & 122.49 \\
\hline $\mathrm{NBD}_{3}$ & 93.30917 & -11.8593 & 18.62118 & -0.63687 & 0.405606 & 22.07695 & 116 \\
\hline $\mathrm{BD}_{1}$ & 93.67027 & -5.702 & 11.67083 & -0.48857 & 0.2387 & 12.98927 & 118.39 \\
\hline $\mathrm{BD}_{2}$ & 94.15993 & -9.45589 & 17.532 & -0.53935 & 0.290899 & 19.91946 & 119.05 \\
\hline $\mathrm{BD}_{3}$ & 93.32179 & -8.78896 & 15.80303 & -0.55616 & 0.30931 & 18.08263 & 1 \\
\hline
\end{tabular}

Consequently, under certain experimental conditions, many of the chemical compounds present in the composition of the detergents may allow the formation certain active binding centers, fact which suggests the possibility of reducing certain specific parameters of the plantlets in the processes of involuntary pollution of the environment.

\section{Conclusions}

In this work the results show that the number of leaves is an indicator which decisively depends on the interaction between the species and the detergent. It was concluded that the analysis of the biometrical parameters constitutes an aspect which determines, directly or indirectly, the resistance of the species of plantlets to the action of liquid detergents.

Ratio between the quantities of chlorophyll $a$ and $b$ and the total quantity of carotenoids (xanthophylls and carotenoids) is an indicator of stress and disturbance of the photosynthesis process in the case of the bean and parsley plantlets.

Moreover, additional investigations showed that the significant decrease in chlorophyll and total carotenoids content was correlated with plantlets height and number of leaves variation.

The chromatic parameters determinations revealed that the change of the color of the plantlets after the absorption of the detergent components by the roots is a dynamic process that also depends on the concentration of the detergent.

This paper is part of a continuing effort to understand the metabolic changes of plants under pollutants action.

\section{References}

[1]. Horn H. A., Bilal E., Ribeiro V. E., Trindade M. W., Baggio H., The pollution impact on the water, soil and plant generated by foundries in Pipapora and Varzeá da Palma, Minas Gerais state, Brasil, Carpathian J. of Earth and Env. Sc., 7, p. 211-218, 2012.
[2]. Leticia Suárez, María A. Diez, Francisco A. Riera, Recovery of detergents in food industry: an industrial approach, Desalination and Water Treatment, p. 1-10, 2014.

[3]. Syeda Uzma, Sarzamin Khan, Waheed Murad, Nadia Taimur, Azizullah Azizullah, Phytotoxic effects of two commonly used laundry detergents on germination, growth, and biochemical chacacteristics of maize (Zea mazs L.) seedlings, Environ Monit Assess, 190, 651, 2018.

[4]. Dragomir Bălănică C. M., Simionescu A. G., Bîrsan I. G., Bichescu C. I., Munteniță C., The assessment of using the sewage sludge in agriculture in Romania, Materiale Plastice, vol. 55, nr. 4, p. 700-703, 2018.

[5]. Zanoschi V., Toma C., Morphology and anatomy of cultivated plants, Ed. Ceres, Bucharest, (In Romanian), 1985.

[6]. Gomes S. M. S., Lima V. L. A., Souza A. P., Nascimento J. J. V. R., Nascimento E., Cloroplast pigments as indicators of lead stress, Engenharia Agrícola, Jaboticabal, 34, p. 877-884. 2014.

[7]. Lichtenthaler H., Buschmann C., Chlorophylls and Carotenoids. Measurement and Characterization by UV-Vis Spectroscopy, Current Protocols in Food Analytical Chemistry, F4: 3.1-3.8, 2001.

[8]. Gang P., Xiu-Lan X., Qian J., Song S., Chang-Jie X., Chlorophyll $a / b$ binding protein plays a key role in natural and ethylene-induced degreening of Ponkan (Citrus reticulata Blanco), Scientia Horticulturae, 160, p. 37-43, 2013.

[9]. Ritchie R., Consistent sets of spectrophotometric chlorophyll equations for acetone, methanol and ethanol solvents, Photosynthesis Research, 89, p. 27-41, 2006.

[10]. Ritchie R., Universal chlorophyll equations for estimating chlorophylls $a, b, c$, and $d$ and total chlorophylls in natural assemblages of photosynthetic organisms using acetone, methanol, or ethanol, Photosynthetica, 46, p. 115-126, 2008.

[11]. C. I. E., Technical Report: Colorimetry, $3^{\text {rd }}$ ed., Publication 15, Central Bureau of the CIE, Vienna, 2004.

[12]. Krystian M., Stanislaw L., Chlorophyll extraction from leaves, needles and microalgae: A kinetic approach, International J. of Agricultural and Biological Eng., 6, p. 107-115, 2013.

[13]. Qingjie D., Dalong Z., Xiaocong J., Xiaoming S., Jianming L., Effects of atmospheric and soil water status on photosynthesis and growth in tomato, Plant, Soil and Env., 64, p. 13-19. 2018.

[14]. Goncalves J. F. C., Marenco R. A., Vieira G., Concentration of photosynthetic pigments and chlorophyll fluorescence of mahogany and tonka bean under two light environments, Braz. J. of Plant Physiology, 13, p. 149-157, 2001.

[15]. Poongodi N., Sasikala T., Effect of detergent on selected morphological and biochemical parameters of green gram (Vigna radiata L.), Biotechnology, 2(7), p. 9-10, 2013.

[16]. Cretu R., Circiumaru A., Murariu G., Effect of Liquid Detergents on the Biochemical Parameters of Some Plantlets, Materiale Plastice, 55, 4, p. 575-579, 2018. 